\title{
DURATION OF STAY IN HOSPITAL OF PATIENTS SUFFERING FROM SCHIZOPHRENIA
}

\author{
BY \\ J. K. WING \\ Medical Research Council Social Psychiatry Research Unit, Institute of Psychiatry, London
}

AND

JOHN DENHAM and A. B. MUNRO

Long Grove Hospital, Epsom, Surrey

During recent years many changes in methods of treatment and in administrative policies have been introduced into mental hospitals. There has been a more intensive use of the physical treatments, culminating in the present preoccupation with the ataraxic drugs. Parallel with this has been the development of habit-training methods, group psychotherapy, the "open door" policy, and the therapeutic community. Finally, discharge policy has been altered, in conjunction with the attempt to minimize the barrier between the hospital and the outside world. At any hospital where this ferment of change has been taking place for a number of years, it should be possible to demonstrate a resulting decrease in the length of stay, and an improvement in the clinical and social status, of patients who formerly would have been regarded as having a poor prognosis. In particular, schizophrenic patients should be shown to have benefited. As part of a programme of work designed to investigate this assumption, the present authors have made a study of two cohorts of schizophrenic patients admitted to Long Grove Hospital.

This hospital is situated in Epsom, Surrey, and is thus about 25 miles away from its catchment area, the East End of London. The composition of the area has not changed during the period under review. It is predominantly working class and some of its social characteristics have been investigated in recent work by the Institute of Community Studies (Young and Willmott, 1957). The hospital has about 2,000 beds.

The first cohort studied consisted of patients admitted between July 1, 1950, and June 30, 1951; these patients were followed up, using hospital records, for 5 years. The second cohort consisted of patients admitted between July 1,1955 , and June 30 , 1956, with a follow-up period of 2 years.

The only comparable study of a single English mental hospital is that made by Shepherd (1957). He compared a cohort of patients admitted during 1931-1933 with a cohort admitted in 1945-47, using a 5-year follow-up period. There was a slight increase (from 29 to 37 per cent.) in the proportion of first-admission schizophrenic patients retained continuously for 5 years in the later cohort, but a decrease (from 73 to 40 per cent.) in the proportion of re-admitted patients so retained. The numbers of schizophrenic patients involved were, however, small.

Kramer, Goldstein, Israel, and Johnson (1955) showed that a larger proportion of patients with functional psychoses (about 75 per cent.) was discharged from the Warren State Hospital in the 2 years after first admission during the period 1946-1950 than at any previous time since 1916, although they were unwilling to state that this was due to the increased use of E.C.T. and insulin coma treatment. Malzberg (1952), investigating the New York State figures, found that about one-half of first-admission schizophrenics were retained continuously for 2 years.

Svendsen (1952) and Kramer and others (1955) have discussed the many factors which may influence admission and discharge from hospital. Important among these is the attitude taken by members of the community which the hospital serves. This was illustrated by Harris and Norris (1954), who found that the admission of patients with milder illnesses following the Mental Treatment Act of 1930 partly accounted for an apparent improvement in prognosis. Since marital status and social class have 
been found to be associated with prognosis in schizophrenia (Ødegård, 1946; Norris, 1956; Brooke, 1957), any alteration in these respects due to change in the way the hospital is regarded may markedly affect the outcome. The education of public attitudes has been undertaken by Macmillan (1958) and Carse (1958) as part of their development of community services. Macmillan states that no schizophrenic patient first admitted during 1956 was resident in his hospital 2 years later, and he considers that this is largely due to the fact that he can supervise patients in their own homes both before and after their hospital stay. However, other factors are no doubt important, in particular new methods of treatment and a more outward-looking discharge policy.

\section{Results of Present Study}

The composition of the two cohorts in terms of age, sex, marital status, occupation (men only), and previous admission to any hospital for mental illness is shown in Table I. None of the differences between the cohorts reaches significance, using the $\chi^{2}$ test, though the increase in male readmissions approaches it $\left(\chi^{2}=3 \cdot 3 ; n=1 ; p=<0 \cdot 10\right)$.*

Table II shows the numbers of patients who were discharged from hospital within 2 years of admission. There was a significant increase (using the $\chi^{2}$ test) in the proportions of males and of re-admitted females so discharged, but no change in respect of females admitted for the first time.

The extent to which patients who were discharged within 2 years of admission were subsequently re-admitted during the 2-year follow-up period is shown in Table III (opposite). There is no significant change in the proportion readmitted in any category.

The mean length of stay in hospital during the 2-year follow-up period (including periods of readmission) is presented separately for the two cohorts, two sexes, and two age groups in Table IV (opposite).

Parametric statistics are not well suited to this type of distribution, but the means shown enable a rough

* Yates's correction for continuity was used in calculating $\chi^{2}$ when the expected frequency in any cell was less than 10.

TABLE I

PATIENTS SUFFERING FROM SCHIZOPHRENIA ADMITTED TO LONG GROVE HOSPITAL IN THE TWO TWELVE-MONTH PERIODS 1.7.50 TO 30.6.51 AND 1.7.55 TO 30.6.56

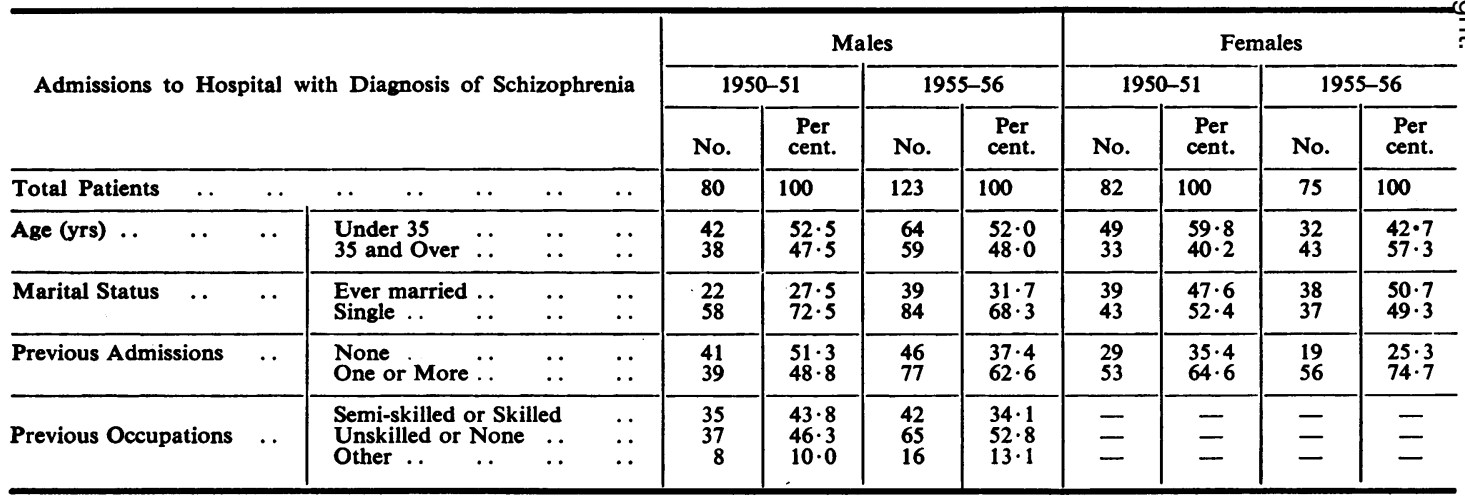

TABLE II

NUMBER OF PATIENTS DISCHARGED AND REMAINING IN HOSPITAL DURING THE 2 YEARS AFTER ADMISSION

\begin{tabular}{|c|c|c|c|c|c|c|c|c|c|c|c|c|}
\hline \multirow{3}{*}{\multicolumn{5}{|c|}{ Progress within 2 Years of Admission }} & \multicolumn{4}{|c|}{ Males } & \multicolumn{4}{|c|}{ Females } \\
\hline & & & & & \multicolumn{2}{|c|}{ First Admission } & \multicolumn{2}{|c|}{ Re-admission } & \multicolumn{2}{|c|}{ First Admission } & \multicolumn{2}{|c|}{ Re-admission } \\
\hline & & & & & 1950 & 1955 & 1950 & 1955 & 1950 & 1955 & 1950 & 1955 \\
\hline Total Patients & .. & $\ldots$ & .. & $\ldots$ & 41 & 46 & 39 & 77 & 29 & 19 & 53 & 56 \\
\hline Discharged $\ldots$ & .. & . & . & . & 28 & 43 & 23 & 60 & 22 & 14 & 27 & 41 \\
\hline \multicolumn{2}{|c|}{ Remained Continuously } & $\ldots$ & .. & . & 13 & 3 & 16 & 17 & 7 & 5 & 26 & 15 \\
\hline \multicolumn{3}{|c|}{ Proportion Per cent. Discharged } & $\ldots$ & .. & $68 \cdot 3$ & 93.5 & 59.0 & $77 \cdot 9$ & $75 \cdot 9$ & $73 \cdot 7$ & 50.9 & $73 \cdot 2$ \\
\hline
\end{tabular}


TABLE III

RE-ADMISSIONS TO HOSPITAL AFTER DISCHARGE WITHIN 2 YEARS OF FIRST ADMISSION

\begin{tabular}{|c|c|c|c|c|c|c|c|c|c|c|c|}
\hline \multirow{3}{*}{\multicolumn{4}{|c|}{$\begin{array}{l}\text { Subsequent Progress of Patients discharged } \\
\text { within } 2 \text { Years of First Admission }\end{array}$}} & \multicolumn{4}{|c|}{ Males } & \multicolumn{4}{|c|}{ Females } \\
\hline & & & & \multicolumn{2}{|c|}{ First Admission } & \multicolumn{2}{|c|}{ Re-admission } & \multicolumn{2}{|c|}{ First Admission } & \multicolumn{2}{|c|}{ Re-admission } \\
\hline & & & & 1950 & 1955 & 1950 & 1955 & 1950 & 1955 & 1950 & 1955 \\
\hline Total Patients Discharged & . & $\ldots$ & $\ldots$ & 28 & 43 & 23 & 60 & 22 & 14 & 27 & 41 \\
\hline Not Re-admitted & . & . & .. & 20 & 39 & 18 & 44 & 10 & 11 & 19 & 27 \\
\hline Re-admitted .. & $\ldots$ & $\ldots$ & . & 8 & 4 & 5 & 16 & 12 & 3 & 8 & 14 \\
\hline \multicolumn{4}{|c|}{ Proportion Per cent. Re-admitted .. } & $28 \cdot 6$ & $9 \cdot 3$ & $21 \cdot 7$ & $26 \cdot 7$ & $54 \cdot 5$ & $21 \cdot 4$ & $29 \cdot 6$ & $34 \cdot 1$ \\
\hline
\end{tabular}

TABLE IV

MEAN DURATION OF STAY IN HOSPITAL DURING THE 2 YEARS FOLLOWING ADMISSION (MONTHS)

\begin{tabular}{ll|c|c|c|c}
\hline \multirow{2}{*}{ Age (yrs) } & \multicolumn{2}{c|}{ Males } & \multicolumn{2}{c}{ Females } \\
\cline { 3 - 5 } & & 1950 & 1955 & 1950 & 1955 \\
\hline Under 35 & $\cdots$ & 12.5 & $7 \cdot 7$ & 12.9 & 11.0 \\
\hline 35 and Over & $\cdots$ & 15.0 & 9.3 & 15.2 & 13.6 \\
\hline
\end{tabular}

comparison to be made between the various groups. The decrease in total time spent in hospital is consistent for all subgroups, but it is clear that the older patients tend to stay longer.

It has already been shown (cf. Table I) that the social class and marital status composition of the cohorts was not significantly different. There has been a trend towards the admission of voluntary rather than certified patients in 1955 compared with 1950 (39 per cent. compared with 30 per cent. voluntary) but this was not significant statistically $\left(\chi^{2}=3 \cdot 1 ; p=>0.05\right)$.

Patients who were single on admission had a worse prognosis in both cohorts when age was taken into account, but there was a significant improvement in the second cohort as compared with the first. The relationships are shown in Table $\mathrm{V}$.

TABLE V

PROPORTION OF PATIENTS REMAINING CONTINUOUSLY IN HOSPITAL FOR AT LEAST 2 YEARS, BY AGE AND MARITAL STATUS

\begin{tabular}{|c|c|c|c|c|}
\hline \multirow{2}{*}{\multicolumn{2}{|c|}{ Age (yrs) }} & \multirow[t]{2}{*}{ Marital Status } & \multicolumn{2}{|c|}{$\begin{array}{l}\text { Per cent. remained } \\
2 \text { Years or More }\end{array}$} \\
\hline & & & 1950 & 1955 \\
\hline Under $35 \ldots$ & . & $\begin{array}{ll}\text { Single } & \ldots \\
\text { Married } & \ldots\end{array}$ & $\begin{array}{l}31 \\
23\end{array}$ & $\begin{array}{l}14 \\
11\end{array}$ \\
\hline 35 and Over & $\ldots$ & $\begin{array}{l}\text { Single } \\
\text { Married }\end{array}$ & $\begin{array}{l}57 \\
38\end{array}$ & $\begin{array}{l}33 \\
22\end{array}$ \\
\hline
\end{tabular}

On the other hand, patients whose previous occupations had been unskilled (the Registrar General's
Social Class V) did not have a worse prognosis than others (for the first cohort, $\chi^{2}=2 \cdot 73 ; n=1 ; p=$ $>0.05$ ). The prognosis for unskilled labourers taken alone improved significantly $\left(\chi^{2}=7 \cdot 43: n=1\right.$; $p=<0.01$ ).

The subsequent history of the sixty patients of the 1950 cohort who remained in hospital continuously for 2 years was that 68 per cent. continued to be resident throughout the next 3 years, only nineteen being discharged during this time.

\section{Discussion}

The figures quoted above appear to show that Long Grove Hospital exemplifies current British mental hospital practice to the extent that schizophrenic patients are being discharged significantly earlier, but also that the patients so discharged are not more frequently readmitted than before. Various explanations may be put forward.

In the first place, it is suggested that community attitudes have altered, in respect both of the illness and of the mental hospital as a proper place of treatment. This process has been helped by the opening of new out-patient clinics where contact with the patient and his family is maintained and admission to hospital arranged in a co-operative rather than a coercive way. However, the difficulties caused by the distance between hospital and catchment area are too great for a satisfactory community service to be developed, and deliberate fragmentation of what used to be a continuous stay is not practicable. No evidence can be shown that a milder type of illness characterized the second cohort studied, nor is the re-admission rate raised. There is no reason to suppose that there have been increased re-admissions to other hospitals. It must be concluded, therefore, that change of community attitudes has not contributed greatly to the improvement that has taken place.

Two main factors remain for consideration: changes in treatment, affecting the actual clinical state of the patients, and changes in discharge 
policy, affecting patients who formerly would not have been considered for discharge.

Between 1950 and 1955, a number of changes occurred of a more or less deliberate and controlled kind. A new Physician Superintendent had been appointed in 1951, the nursing services were reorganized, and enlarged, increased and more efficient use was made of E.C.T., insulin coma, and leucotomy, and a more outward-looking discharge policy was adopted. Social work was also more emphasized, though the tiny establishment of psychiatric social workers made improvement in this field very difficult. During the past two years Chlorpromazine, Reserpine, and other drugs have been used on a large scale, and methods of group treatment have been introduced. Drug treatment of outpatients may have had an effect in keeping down re-admissions during the second follow-up period. It is difficult not to attribute some of the improvement to alterations in clinical practice. However, questions of this kind can be decided only by specific on-going studies.

So far as discharge policy is concerned, there has undoubtedly been a major change. G. W. Brown (personal communication) reports that, in the early part of the period under consideration, patients who had no visitors after their admission to hospital were significantly more likely to remain in hospital continuously for 2 years, and it is this group that accounts for some of the improvement in more recent figures. The assumption is that a substantial proportion of such patients remained in hospital because they had no home, and that nowadays other arrangements may be made for them.

The question of value remains for discussion. To what extent are patients being discharged who should remain in hospital? In a recent study of schizophrenic patients discharged after 2 years in a mental hospital, Brown, Carstairs, and Topping (1958) found that 17 per cent. could be said to be a severe, and 28 per cent. a moderate, social liability. However, the fact that readmission to Long Grove has not increased is reassuring in this respect. The scientist must perhaps suspend judgment, but the clinician will argue that every discharge from hospital involves the calculation of a risk, and that one can be over-cautious as well as over-optimistic. The point can only be settled by further research.

\section{SUMMARY}

Of a cohort of 162 schizophrenic patients admitted to Long Grove Hospital during the year July, 1950, to June, 1951, 62 (38 per cent.) stayed in hospital continuously for 2 years. The equivalent number for a cohort of 198 patients admitted 5 years later was forty (20 per cent.) For first admissions only, the numbers were twenty out of 70 (29 per cent.) and eight out of 65 (12 per cent.). The decrease was most marked for first-admission males and least for firstadmission females. There was improvement even in hose groups of patients whose prognosis seemed likely to be poor by reason of age, marital status, or social class. Patients were not more frequently re-admitted during the second 2-year follow-up period, although they had been discharged earlier. It has been argued that, of the many possible causes for such a change, intra-hospital factors are likely to have been of most importance for this particular sample, but furtheb research is required to determine with precision the relative influence of the various factors considered and the value of the recorded results.

\section{REFERENCES}

Brooke, E. (1957). Paper given at Int. Cong. Psychiat., Zürich. Brown, G. W., Carstairs, G. M., and Topping G. (1958). Lancet, 2,685 .

Carse, J., Panton, N. E., and Watt, A. (1958). Ibid., 1, 39.

Harris, A., and Norris, V. (1954). J. ment. Sci., 100, 241.

Kramer, M., Goldstein, H., Israel, R. H., and Johnson, N. A. (1955). Publ. Hlth Monograph, No. 32, Washington, D.C.

Macmillan, D. (1958). Lancet, 2, 201.

Malzberg, B. (1952). Ment. Hyg., 36, 104.

Norris, V. (1956). J. ment. Sci. 102, 467.

Odegård, O. (1946). Ibid., 92, 35 .

Shepherd, M. (1957). "A Study of the Major Psychoses in an English County". Maudsley Monograph, No. 3. Chapman and Hall, London.

Svendsen, B. B. (1952). "Psychiatric Morbidity among Civilians in Wartime". Acta Jutlandica (Aarsskrift for Aarhus Untversitet), 24, Supplementum A. Munksgaard, Copenhagen.

Young, M., and Willmott, P. (1957). "Family and Kinship in Eas London". Routledge and Kegan Paul, London. 